\title{
Finally in the Spotlight: How Contemporary Learning Theory is Saving Education Online During COVID
}

\author{
Paula Charbonneau-Gowdy, Jaime Pizarro and Danisa Salinas \\ Universidad Andres Bello, Santiago, Chile \\ paula.charbonneau@unab.cl \\ jaime.pizarro@unab.cl \\ danisa.salinas@unab.cl
}

\begin{abstract}
A surge of literature documenting myriad challenges being faced online during the COVID pandemic strongly suggests that e-learning scholarship has fallen short of conveying an understanding of how to build highly effective e-learning spaces. Recent stories from practitioners abound with reports of absenteeism, cameras and microphones turned off, inaction in forums and a general reticence on the part of learners to engage online. Where have we missed the mark in our efforts to have contemporary e-learning theory affect online practice? Scholarship is indicating that the root of the disconnect often lies in the conventional instructional designs being used in these spaces and the teaching, learning and assessment practices they support. In response to such issues, we conducted a qualitative action research initiative to apply an instructional design (ID) model, based on contemporary learning theories and goals, in a teacher education program in Chile. The study took place in 2020 over 2 academic semesters. In this study, we focussed on the impact of these changes on a small group of firstyear Pre-service Teachers (PSTs, $n=17)$, experiencing online learning for the first time. Pre and post interviews, an openended questionnaire, field notes from self-assessment portfolios and observations of the digital environment were used to collect data. We also draw on two other data sources in the same context: 1) an earlier report of this initiative that focussed on the Teacher Educators (TEs) in the same program $(n=4)$, and 2) survey data collected in a preparatory stage of the action research on the experiences of the greater university student body $(n=1,054)$. Evidence revealed that initially learners' epistemological views were heavily influenced by the teacher-centric and content-driven pedagogies of earlier schooling. Yet, results also showed that the contemporary learning design framework had positive implications for many students' social, cognitive, and metacognitive competencies. Clear signs of more active investment in social interactive learning online on the part of the PSTs and of flexible, self-directed behaviours were evidenced. The results of this study provide an empirically based practical solution for connecting current learning theory to practice in online contexts, solutions that could endure even once the challenges of the pandemic crisis are behind us.
\end{abstract}

Keywords: instructional design model; online learning; higher education, COVID-19 pandemic; contemporary learning theories

\section{Introduction}

Few would argue that the chaos and disruption caused globally in many areas of society by the pandemic have been especially felt in the field of education. With more than 1.3 billion students out of school worldwide in the early stages of the pandemic (Seels 2020), teachers and their institutions in most countries have been scrambling to ensure that formal learning continues. The quality of that learning is another matter. Indeed, according to media reports and judging from the outpouring of recent scholarship, there have been serious challenges (Deihl, 2020, Scull et al. 2020; Flores and Gago, 2020). E-learning scholars have long predicted the potential conversion of a large part of conventional education to online spaces. Yet, despite this forewarning, the transition that abruptly began in 2020 both to synchronous and asynchronous learning has been met with skepticism by some (Moralista and Oducado, 2020; Judd et al. 2020), and resignation or mere compliance by others (Ribiero, 2020). Neither reactions are indicative of the conditions for offering opportunities for quality learning. Not surprisingly, Joshi et al. (2020) have claimed the instructional achievement of online learning to be debatable.

Of course, reservations vis-à-vis online learning and its effectiveness did not arise only of late. Scholars in the last twenty years have documented similar signs of resistance, both passive and active, to technology-supported learning well before and up to the time the pandemic struck. In a recent meta-analysis of the literature on online learning, Castro and Tumibay $(2021$, p.1) uncovered insights from the analysis of thirty studies that might suggest the roots of this resistance. The researchers found three themes that can explain the tensions related to online learning: 1) comparisons drawn between online learning and traditional face-to-face settings; 2 ) factors related to online learning delivery; and 3) factors pertaining to institutional adoption of online learning. In terms of comparisons, debates on the advantages of online versus face-to-face learning have abated somewhat in scholarship, at least prior to the pandemic. Indeed, a large body of research in the last 10 years has extolled the benefits of online learning over conventional learning, especially in higher education settings (Garrison and 
Kanuka (2004); Charbonneau-Gowdy, 2018). In relation to the adoption of online learning, here too there has been movement. Statistics in the last decade are clearly indicating a significant increase of online distance learning being incorporated in higher education (HE) institutions (Allen et al. 2016), a fact that can be equated to its growing acceptance.

Ironically, with the global move to online learning in 2020, both comparison and adoption arguments have become mute points. Naidu (2020, p. 425) notes that criticism of the veracity of online learning compared to conventional classroom learning no longer matters. So too, with senior management in most institutions deciding to go fully online to remain viable, a question of institutional support is redundant. On the other hand, from the abundance of research documenting the educational challenges in the new evolving reality and the many stories being told (UNESCO, 2021), uncertainty and confusion around the delivery of online learning is at the very heart of the issues being faced, and the hesitancy being felt. Delivery, like the contexts in which it operates is a complex construct that mirrors complex conditions - pedagogical, technological, social, cultural and economic, just to name a few.

How can we respond to questions about delivery challenges in view of the 'forced' move to online learning during the pandemic? How can we enhance a more universal and active uptake of understanding and knowledge from e-learning scholarship that we have built thus far for ensuring delivery of effective learning online? These questions become particularly relevant considering the possible future of education post pandemic. In recent World Economic Forum reports (Whiting, 2021, Schleicher, 2021), those examining the future of education suggest that there is no turning back. In a survey of 27,500 adults in 29 countries when asked about their visions of higher education being conducted in their country in five years, $72 \%$ expressed the belief that online learning will be as prevalent as in-person learning, if not more. Given the continuing salient role online learning will apparently play in higher education, what concrete, practical, and indeed critical, steps can we take to connect theory to practice more effectively than we have done in the past? Even reviewing the deluge of studies appearing in e-learning scholarship during the transition to online learning due to COVID, there appears a paucity of empirical evidence to support a systematic, theoretically based design framework that could address the most salient issues that these studies are documenting about online contexts.

Increasingly, grounded research into applying ID models based on contemporary e-learning theories into practice is being considered our best hope for transforming online education, both teaching and learning. It is through aligning this modality of education with a constructivist, learner-centred, cooperative pedagogy in practice, that learners are offered rich opportunities for deep learning (Garrison and Cleveland-Innes, 2015, Picciano, 2017). Calls for these kinds of initiatives have been growing steadily in scholarship (Pange and Pange, 2011; Branch and Dousay, 2015; Margaryan, Bianco and Littlejohn, 2015; Medina, 2018) and more so than ever during the pandemic. Momentum has been gathering to respond (Adinda and Mohib, 2020).

In searching ways to find answers to these issues and reflections, our goal was to put in place action research in which we applied a made-to-measure contemporary theory-based instructional design framework to a pedagogy program in Chile. The program, like many others globally, was forced to move online abruptly due to the pandemic. In an earlier study we reported on the impact of this change on Teacher Educators (TEs) in the program (Charbonneau-Gowdy, Pizarro and Salinas, 2021). In this earlier 10-month study, we focussed on 4 TEs' experiences as they adopted the new contemporary theory-based design in their practices online. The results of the study showed the TEs' long-held teacher-centric identities and approaches sometimes interfered in this trajectory. Yet, their heightened critical awareness of the ineffectiveness of traditional teaching paradigms in online settings combined with their grounded efforts and perseverance, resulted in the TEs moving progressively away from teacher controlled to learner-driven practices in the new online setting. Their bold steps to connect theory to their approaches and practice showed parallel changes to their identities as online instructors, evidenced by increased confidence, courage, creativity, and resilience. There was also evidence of the TEs assuming $21^{\text {st }}$ century teacher roles as trusted learning guides and facilitators of strong learning communities (Riverin and Stacey, 2008).

In the present study conducted in the same context, we focus on the PST learners and on their learning. An important preparatory step to the action research involved collecting data from the larger university body of students in the institution on their reactions and learning experiences in the sudden move to online learning. The emerging findings from this stage in the process helped precipitate the action research initiative in the pedagogy program. 
With this impetus and our goal in mind, the following questions were used to guide the study:

1. What are the perceptions of a small group of PSTs in Chile of a sudden move to online learning due to the pandemic?

2. How has this move impacted their attitudes towards and engagement in learning?

3. What influence, if any, does applying a contemporary e-learning design model based on sociocultural theory and goals in the teaching practices of the online program have on their present and future identities as learners and on their investment in learning?

In the next section, we describe the theoretical framework and literature that supported the instructional design model we collaboratively built with instructors and applied in the online program. We then explain our methodology including details about the context, research design and data collection. A discussion of the analysis and findings follow and we end the paper with acknowledging the limitations of the study and suggesting its implications for future research.

\section{Theoretical Framework and Literature Review}

The increasing visibility that contemporary learning theories, especially those based on sociocultural perspectives rooted in Vygotskian principles (Vygotsky, 1981) and 21 st century goals (Voogt et al., 2013), have gained in education scholarship over the last two decades, is encouraging. These theories and goals are being recognized for their value in: a) placing learners and their agency at the centre of learning processes; $b$ ) acknowledging that learning is a complex, social interactive phenomenon; $c$ ) involving learners in communities that collaborate on co-constructing knowledge based on their own contexts and experience; and d) having important implications for learners' competencies, and their highly dynamic identities, and their engagement in learning.

\subsection{Impediments to contemporary theories in online learning}

Growing numbers of scholars in e-learning contexts over the last decade have been preoccupied by these socialbased theories and goals. Scholars like Yuan and Kim, 2014, have shown the upsides of applying these theories in practice in online spaces - increased learner satisfaction and completion rates, as well as the downsides if they are ignored - feelings of isolation, lack of active engagement and attrition. Indeed, some e-learning scholars argue that the failure of scholarship to turn mindsets in traditional learning contexts towards embracing these theories and goals, could be overcome in virtual settings (Garrison and Kanuka, 2004; Garrison and Vaughan, 2013, Charbonneau-Gowdy and Herrera, 2019; Prinsloo, 2016). Yet, such aspirations for both traditional and online contexts have been slow to materialize (Brown and Charlier, 2013). As a result, at least in online settings, a focus on self-paced, autonomous learning in isolation, information-based content and teaching, as well as traditional assessment practices, are often the default. A significant body of emerging research and examples being documented during the COVID pandemic, are a case in point. The lack of social interaction, constructivist learning and community building that are reflected in the practices in the contexts of many of these reports can help explain some of the major challenges: disengaged and anxious learners, high levels of attrition and disappointing learning results (Flores and Gago, 2020). In our view, the key shortcoming of much of this albeit valuable scholarship is that it stops short of providing empirical evidence of changes and the application of theory-based pedagogical practices that could help reverse such issues.

One way to explain the lack of uptake of contemporary theories and goals in online learning on the part of practitioners could be by the paucity of empirical evidence that provides concrete examples of these theories in practice. As Yuan and Kim (2014, p. 221) point out what is needed is "a set of guidelines...but also the steps to reaching the goal". Examples of such efforts have been emerging gradually in a cross-section of fields and contexts (Garrison and Vaughan, 2013; Margaryan, Bianco and Littlejohn, 2015; Philipsen et al., 2019), albeit in blended learning scenarios. According to Charbonneau-Gowdy and Herrera (2019), these emerging examples of putting theory into practice are proving to lead to multiple benefits - increased learner engagement, selfdirected learning and regulation skills, creativity, and critical thinking.

The slow uptake of contemporary learning theory and goal-based online practice could also be placed on the lack of realistic ID-based models to guide this transition. By ID, we reference a systematic approach to analyze, design, develop, implement and evaluate instruction, i.e. both learning and teaching (Seels and Richey, 1994; Branch and Dousay, 2015). Smith et al. (2016) argue that without these clear guiding design frameworks, instructors' practices in online learning settings fail to promote agency, social interaction, social cognitive 
presence, and identity empowerment underlining contemporary theories and goals. Instead, as pointed out above, practitioners often fall back to conventional instructional designs ingrained in their practices in traditional classrooms. Indeed, Adinda and Mohib (2020) posit that the benefits of the various and expanding affordances offered by technology in theory are not automatic, but rather dependent on the essential epistemological conformity that exist in designs, approaches and practices in online spaces. In the context of the current study in which a pedagogy program was being offered online for the first time in virtual spaces, the confluence of the ID, approaches and practices to reflect contemporary theory in the virtual spaces held particular importance. Not only could the approaches and practices in the online spaces have a serious impact on the PSTs' pedagogical development, but also seriously influence their future profiles and effectiveness as aspiring professionals for the new educational aftermath of the pandemic, a future in which online learning could be the norm.

\subsection{Current online learning theories and models}

Scholars working to develop theories of online education derived from sociocultural principles and goals have offered a variety of perspectives and models. The Community of Inquiry (Col) theory developed by Garrison, Anderson and Archer (2000) is closely tied to Lave and Wenger (1991) and Wenger's (1998) communities of practice and situated learning concepts. Based on this model, learning is a process that results from a deepening participation in a learning community. The Col model supports IDs in which online learning takes place in active environments where instructors and students share ideas, opinions and ideas and where social presence is demonstrated through engagement in discussion boards or forums, blogs and videoconferencing. In the context of our study, a focus on building strong communities of learners (Riverin and Stacey, 2008) and active participation of PSTs and TEs were firmly built into the new direction for program courses.

Anderson's (2011) and Picciano (2017) offer further theory-based models for online education that had relevance to our study. Of interest in Anderson's (2011) model is the emphasis it places on both Net-based synchronous and asynchronous activities. The model draws attention to the richness of these environments for the development of social skills, collaborative learning of content and the establishment of personal connections among participants. One of the limitations of the model is that it does not consider the powerful affordances of videoconferencing for face-to-face sessions that existed in our study. Picciano's Multimodal Model for Online Education (2017, p.178), is based on the premise that "pedagogy drives approaches that will work best to support student learning". The model is built on a framework of seven intersecting components that comprise the essential opportunities for learning available in a quality online program - that is through media content, reflection, collaboration, assessment, dialogue, self-directed learning and social/emotional support. These opportunities underscore the aims of the design applied in our study which were: a) to build community; b) to influence the social/emotional makeup of student profiles, i.e. their identities; and c) to promote the collaborative development of $21^{\text {st }}$ century skills.

\subsection{Applying theory to practice}

In considering ways to apply new design models that will connect theory to practice, Branch and Dousay (2015) suggest five well-established conceptual phases, so-called ADDIE, to guide the actualization process: analyze, design, develop, implement, and evaluate. The authors have used these guiding phases to evaluate the application of over 150 instructional designs for their relevance and effectiveness. It is important to point out that these phases should not be confused with a learning design in and of itself, but rather its implementation and evaluation. These 5 phases supported the development of the ID used in our study and its concrete application in the teaching and learning processes taking place online. It is worth noting that most newly developed IDs, as Branch and Dousay (2015, p.89) point out, are never applied or much less evaluated. It was the practical application and validation of the contemporary theory-based design developed in the context of our study, albeit a modified existing model, that we considered important to its future usefulness as a pragmatic tool for sustained use.

In the context of the study, ensuring the validity and applicability of our design met three objectives: a) that the PSTs had an opportunity to build a collaborative framework to guide their present and future practice; 2) that sociocultural principles and $21^{\text {st }}$ century goals were being applied in the online learning pedagogies; 3 ) that the PSTs would potentially benefit from these principles and goals. A recent study conducted by Margaryan, Bianco and Littlejohn, (2015) provided a framework (see Table 1) in our analysis of the value of our theory-based design in practice. In their study, the authors assessed and compared the ID quality of 76 Massive Open Online Courses (MOOCs). The ten-principle framework, of interest to our study, is built on key ID theories and models (Merrill, 2013; Margaryan, Bianco and Littlejohn, 2015, p.78-81). A systematic review of 22 contemporary instructional 
theories confirmed support for the list of principles that make up the framework (Gardner, 2011a). It is worth noting that the majority of the MOOC courses analyzed by the authors using this framework "faired poorly" in aligning contemporary theory-based design to online practice. We found the framework and the key questions used in their analysis (See Table 1) applicable to our study and a way to assure the successful application of the sociocultural perspectives and $21^{\text {st }}$ century goals we were attempting to apply. Their study also allowed us to draw inferences as to the causes of the challenges that the PSTs, and indeed their educators, were facing in our study and with this knowledge work towards design solutions.

Table 1: Framework for the evaluating instructional designs in practice online (Margaryan, Bianco and Littlejohn, 2015)

\begin{tabular}{|l|l|}
\hline \multicolumn{1}{|c|}{ Guiding Principle } & \multicolumn{1}{c|}{ Description } \\
\hline Problem-centred & Learners learn skills in the context of real-world problems \\
\hline Activation & Learners activate their existing knowledge and skills for developing new skills \\
\hline Demonstrated & $\begin{array}{l}\text { Learners learn when exposed to 'real' examples of new skills to be learned rather than } \\
\text { information. }\end{array}$ \\
\hline Application & Learners have opportunities to apply their new skills to solve problems. \\
\hline Integration & Learners have opportunities to reflect on, discuss and defend their new skills \\
\hline Collective Knowledge & Learners contribute to collective knowledge \\
\hline Collaboration & Learners collaborate with others to build knowledge \\
\hline Differentiation & Learners have options according to their individual needs \\
\hline Authentic Resources & Learners are put in real world situations \\
\hline Feedback & Leaners are given regular feedback \\
\hline
\end{tabular}

\section{Methodology}

\subsection{Context and Participants}

The action research study took place in 2020 with a group of 17 first year undergraduate students and their 4 full-time Chilean teacher educators in the context of an EFL 4-year teacher preparation program. Since the decision to move all programs to online learning in the institution had come at the beginning of the academic year, most PST students in the group had never met their TEs nor their fellow classmates face-to-face. The program included a variety of course subjects: Phonetics, Language in Use, Writing, Reading, Speaking and Listening.

Chile is one of only three members of the OECD in Latin America. The advancement of English is considered a priority of the government and many young people are lured to the English pedagogy program with attractive national scholarships. While the country is economically stable, the system of education is still evolving to meet higher educational standards reflective of developed countries - a goal which many suggest is and will be determined by the quality of its teachers. Most students, including the pre-service teachers in the institution are first generation university attendees and come from clearly divided socio-economic backgrounds. Due to this reality, disparities exist in terms of access to technological resources and internet and in terms of the cultural capital students bring to their study programs.

During 2020, the government imposed several periods of enforced lockdown. Citizens in the major cities were restricted in their movements during the day, most confined to their homes with outings permitted during specified periods and with government-issued passes. COVID case counts and deaths were relatively high for most of the year although as the second semester ended, the situation improved as record numbers were being vaccinated. The global pandemic crisis that hit the country and the angst it caused was compounded by the previous year when major violent student strikes and social unrest in a call for reform closed schools, universities, and many businesses for an extended period in the country, most particularly in the capital city. The general malaise and fear this period had caused among Chileans was still being strongly felt at the beginning of 2020 when the pandemic struck.

\subsection{Research Design}

The research design consisted of two main phases in which the five core ADDIE elements or steps of implementing instructional design were conducted. These two phases aligned with the two semesters in 2020 in the Chilean context. Table 2 provides an overview of the Research Design and the data collection process. The first phase, March to July 2020, served as a period of analysis. In a preparatory step to the study, we had distributed a survey to the wider undergraduate student body $(n=1,054)$ at the university to understand the 
context and the experiences students were having with the abrupt move to online learning. Armed with the general findings from the analysis of the survey data, we then turned our attention to the experiences of a subset of the student body. Our lens was aimed at a small group of PSTs and the exposure to learning and teaching they were having in their first-year courses in the EFL Pedagogy program. We employed individual interviews, observations, a questionnaire, and field notes from online activity as the basis for further analysis of the PSTs' realities, needs and their learning context in this first phase/semester.

The second phase, August to December 2020, involved the design, development, and implementation of the new ID. In this phase, TEs and the lead researcher mediated the key elements of the design and its application. The various changes that were to be made to the design of their courses and their practices based on sociocultural theories and $21^{\text {st }}$ century goals were discussed and agreed upon. Essentially, deep ID changes included: a) launching strategies for building learning communities to increase learner involvement in the synchronous sessions; b) providing increased opportunities and resources for student collaboration on both learning assignments/projects and assessment processes; c) using group project media and student generated material as course content; d) incorporating problem-based strategies in course forums to promote a student exchange of ideas and opinions; e) assigning mentor and teaching roles to students; f) building individual and group reflection opportunities into course plans; g) increasing choice and options for student decision making; and $h$ ) improving the quality and incidences of instructor-student and peer feedback.

Strategies and innovative ways intended to incorporate the newly adapted design were also negotiated among the instructor and the lead researcher. Importantly, these plans involved decision making about the evaluation of changes to learning both on an ongoing basis throughout the semester (formative) and at the end (summative). Over the second semester, the implementation of the new instructional design took place in each course. As with the first phase, an understanding of the perceptions and experiences of the PSTs were collected through individual interviews, observations, and field notes.

Adhering to strict ethical guidelines played an integral part in this design - informed consent, the use of pseudonyms and freedom on the part of students to abstain or withdraw from the action research process.

Table 2: Phases of the Study and Data Collection

\begin{tabular}{|c|c|c|}
\hline Phases of the study & Type of Data & Description \\
\hline \multirow[t]{3}{*}{$\begin{array}{l}\text { Phase 1: } \\
\text { Analysis } \\
\text { March - July } \\
2020\end{array}$} & $\begin{array}{l}\text { Interviews } \\
\text { (online) } \\
\text { Field Notes }\end{array}$ & $\begin{array}{l}\text { Results of 25-item survey of online experiences of greater } \\
\text { student body }(n=1,054) \text {; PST's digital Self -Assessment } \\
\text { Portfolios ( } n=17)\end{array}$ \\
\hline & Questionnaire & $\begin{array}{l}\text { End-of -semester open-ended probe of PSTs' experiences in } 1^{\text {st }} \\
\text { semester }(n=17)\end{array}$ \\
\hline & Observations & $\begin{array}{l}\text { TE's observations of online classes; Digital activity in online } \\
\text { forums and google drive }\end{array}$ \\
\hline \multirow{3}{*}{$\begin{array}{c}\text { Phase 2: } \\
\text { Design, Development, } \\
\text { Implementation and Evaluation } \\
\text { August }- \text { December } \\
2020\end{array}$} & $\begin{array}{l}\text { Interviews } \\
\text { (online) }\end{array}$ & $\begin{array}{l}9 \text { Recorded end-of-semester Zoom individual and group } \\
\text { interviews }\end{array}$ \\
\hline & Field Notes & $\begin{array}{l}\text { PST's digital end-of-year Self-Assessment Portfolios; attendance } \\
\text { records ( } n=17)\end{array}$ \\
\hline & Observations & $\begin{array}{l}\text { TE's observations of online classes; Digital activity in online } \\
\text { forums and google drive }\end{array}$ \\
\hline
\end{tabular}

\subsection{Data Collection and analysis}

We situate our study within the qualitative paradigm. We recognize the epistemological advantages of researching within this methodological area for gathering a deeper understanding of the implications of change to educational settings and for uncovering participant voice (Denzin and Lincoln, 2005). Although tools available within this methodology, i.e. in-depth interviews, field notes, observations, were the primary source of data, we also employed a numbers-based, Likert-scale, survey typical of quantitative inquiries in the preparatory phase. 
The triangulation of data gained from: a) the survey of the general student body $(n=1,054)$ about their new online experiences, conducted in the preparatory stage of this study; $b$ ) the previous qualitative inquiry in the same context that centred on the experiences and perceptions of the TEs with the new ID (Charbonneau-Gowdy, Pizarro and Salinas, 2021); and c) data that emerged from the focus on PSTs in this present study, adds to the rigour and the validity and reliability of its findings. These combined data sources provide a fuller picture of the impact of the new ID-based approach and strong empirical evidence of what was taking place in the context of learning online in 2020 for learners in this HE institution.

A survey was distributed to the general university student body $(n=1,054)$ during the first semester of 2020 . The survey was intended to gain student perceptions of the move to online learning initially and after two semesters. The survey consisted of a 25 -item Likert scale questionnaire. Topics addressed in the questionnaire included the following: reactions to the use of technology, online course content, peer and instructor interaction, instructional practices, and evaluation. Descriptive statistics were employed to analyze the data tabulated. The analysis of these statistics offered insight into the overall perceptions and experiences of the general student body in the transition to a fully distance learning modality.

As mentioned above in the description of the design (Table 2), the qualitative data tools used as data sources in both phases of the study included: mid and end-of-year interviews, a student questionnaire, observations of digital environments and field notes. Field notes consisted of i) digital activity online; ii) individual PSTs' expectation questionnaire ( $n=17)$; and iii) end-of-year self-assessment journals $(n=17)$. The student questionnaire conducted after the first semester gathered feedback from student PSTs about their experiences online during the first cycle of the study whereas results from the second provided general information about their first year in the program.

The qualitative data was analyzed by the lead research with cross-referencing support from two of the TEs and using a combined inductive-deductive process (Miles, Huberman and Saldaña, 2014). After establishing a conceptual framework, a series of iterative steps were taken: a) inspecting the data sets to determine those data that could inform the research questions; b) multiple readings and considerations of the data sets; c) condensing and coding the data for key concepts and ideas that related to the theoretical framework and literature review; d) identifying and refining the salient or common themes from the coded data; e) re-forming a conceptual framework that could then be corroborated by the findings. Descriptive statistics were employed to analyze the data tabulated from the survey. This analysis provided an overall view of the general student body about their initial experiences online. These perceptions helped to corroborate the perspectives being voiced by the PSTs and offered insight to our analysis.

\section{Analysis and Findings}

The initial impetus for launching the study was a combination of a) observations and experiences that TEs were voicing about their online courses and b) the results of the first survey distributed to the larger student body. Early results from the survey indicated that students were reporting: a serious decrease in interactions with both teachers fellow peers; a deep decline in opportunities to engage in discussion in courses; feelings of increased loss of connection with teachers; lack of confidence in the ability to perform well on assessments and to learn.

Compounding these findings, were disturbing signs in the context of the pedagogy program that illustrated the severity of the situation: students' poor attendance records, lack of involvement in online synchronous sessions, inactivity and failure to comply with required assignments in the online asynchronous platforms, general despondency on the part of many students for online learning, and an over-dependency on TE's efforts for their learning. In discussions between TEs and the lead researcher held near the end of the first semester in 2020, it was decided that immediate action was needed. As one of the TE's shared: "[We are] forced to make changes and rethink our effectiveness....and to move beyond our comfort zones" (Charbonneau-Gowdy, Pizarro and Salinas, 2021). Rather than adding to the body of literature being reported at the time documenting similar issues due to the sudden move to online learning, the TEs and lead researcher shared a commitment to apply deep pedagogical changes to the program's ID and collect empirical evidence of the results. A key problem we were seeing at the time with much of the immense body of valuable research being generated in response to COVID's impact on educational contexts, was that it focussed generally on reports of challenges and yet producing a paucity of empirical evidence of ways to respond to these issues. Thus, with the support of macro and meso administration, critical to change (Charbonneau-Gowdy and Chavez, 2019), the newly adapted ID was 
applied to first-year students' courses in our English pedagogy program during the second semester and results were documented.

Changes to instructional practices based on the new design were accompanied by changes uncovered in learners' online identities and their investments in learning over the duration of the study. By investment, we reference Norton (Darvin and Norton, 2016) who developed the construct to mean a commitment to learning based on learners' intentional choice and desire. Two themes emerged from the data sets that demonstrate the trajectory of these changes: learners' attitudes, behaviours and learning during the first semester and learners' attitudes, behaviours and learning in the second semester.

\subsection{Learners' attitudes, behaviours and learning during the first semester}

It was clearly observable from the blank screens, muted microphones and frequent empty chat and forum spaces in the first semester that the PSTs were experiencing feelings of reticence vis à vis learning online. It could be speculated that some of these issues were due to technical, connectivity or family contextual problems, as reported elsewhere (OECD, 2020; UNESCO, 2020; Ribiero, 2020; Flores and Gago, 2020). Yet, data from the various data sets in the pedagogy program, corroborated by quantitative data from our large university-wide survey, suggest a deeper explanation of the PSTs' visibly disengaged behaviours. Hesitancy to speak and engage in discussions were explained by some PSTs to be due to their fear of correction, to lack of confidence in exposing their written communication to peers in the online forums or to tensions that existed in class as teachers struggled to adapt to the new modality. Survey results of the larger student body reflected these concerns: $69.7 \%$ of students reported feeling very or somewhat more hesitant about speaking in online classes compared to 'regular' classrooms; $83.6 \%$ indicated they had fewer possibilities to speak; only $61.5 \%$ felt that their teachers attempted to encourage speaking; a low $28.6 \%$ reported being able to establish a connection with their professors.

A closer analysis of such attitudes and their corresponding behaviours indicates an absence of a strong community of learning in the online classrooms which is pivotal to learner engagement and completion rates (Yuan and Kim, 2014). Indeed, when asked what students missed most about in-person classes, one PST responded: "The social interaction because it is what makes the classes more interesting, and you feel like part of a community." (Questionnaire, July, 2020). Similarly, among the general student body, $74.4 \%$ indicated that they lacked contact with their fellow classmates and $87 \%$ interaction with their professors. When reflecting on the group of her peers in the online classroom, one PST poignantly remarked: "I feel we're just minding our own business." (Interview, July, 2020). These words provide an image of the students in the group attempting to learn in isolation contrary to social learning theories and thus missing out on the deep learning that occurs through interaction with others (Vygostky, 1981; Yuan and Kim, 2014).

Indeed, in the end-of-term interviews, many of the PSTs openly expressed dismay over their learning progress in the first semester. One PST poignantly observed: "I don't feel like I've acquired much knowledge, I don't feel like I'm making any progress at the level of my English either" (Interview, July 2020). This individual's disappointment in the lack of progress over the first semester was also repeated in the responses to the survey. $84 \%$ of respondents reported that they felt that they had learned less. A surprising revelation from the data sets was an indication that some PST students, and others in the general student body (94\%!) according to survey results, adopted more autonomous attitudes towards their learning. Perhaps isolation and/or additional time saved in the absence of commuting might explain this change in some students. After all, many institutional goals, at least in Chile, aspire to promote this trait in students. Yet, $21^{\text {st }}$ century goals would suggest that working predominantly alone in isolation is counter to the kinds of skills education should be building. Instead, working in teams, sharing ideas and building knowledge are key prerequisites for the new workplace realities students will need to face. Not surprisingly, survey results of the larger student body, who also had indicated their feelings of isolation, showed that $83.5 \%$ felt a lack of confidence in their ability to perform well on assessments and even $68 \%$ questioned their ability to learn in the online program setting.

\subsection{Learners' attitudes, behaviours and learning in the second semester}

Phase 2 of the study was marked by a move to new ID-based practices. Analysis of the substantial data that emerged in this phase revealed salient and evolving deep changes to the PSTs identities and investment as evidenced by their attitudes, behaviours, and learning. In Table 3, we draw a conceptual model that concisely synthesizes the findings in this part of the study. In the table, the practical application of key principles of a contemporary learning ID (Margayan, 2015) in these roll-out changes are connected to changes revealed by the 
PSTs. We support this analysis by providing some representative excerpts from the data. The table is followed by a more detailed description of this analysis.

Table 3: Tying changes in design practices to changes in learners and learning

\begin{tabular}{|c|c|c|}
\hline $\begin{array}{l}\text { Contemporary } \\
\text { Theory Guiding } \\
\text { Principles } \\
\end{array}$ & Examples of Changes to Practice & Changes in attitudes, behaviours and learning \\
\hline Problem-centred & $\begin{array}{l}\text { Current issues from online media sources } \\
\text { rather than pre-set textbook content used to } \\
\text { provoke discussion among PSTs in } \\
\text { synchronous classes }\end{array}$ & \multirow{10}{*}{$\begin{array}{l}\text {-Openness to novel ways and new ideas and } \\
\text { broadened perspectives of effective learning } \\
\text { practices: } \\
\text { Students said they liked having real things to } \\
\text { read [and discuss] that were happening in the } \\
\text { real world at the time. (Interview with TE, Dec. } \\
\text { 2020) } \\
\text { - Trusting in community support and valuing } \\
\text { learning from others: I am grateful of every } \\
\text { recommendation and every feedback...(PST } \\
\text { portfolio, Nov. 2020) } \\
\text { - Increased responsibility for learning and } \\
\text { sharing knowledge - e.g. groups of PSTs } \\
\text { volunteer to teach theory to their peers in } \\
\text { replace of TE lectures; also significant number of } \\
\text { assignments submitted online } \\
\text { - More active involvement in forums and sharing } \\
\text { knowledge as shown by increased activity in } \\
\text { forums } \\
\text { - Obvious signs of deeper thinking (cognitive } \\
\text { development): shown in formulating questions } \\
\text { and opinions (cognitive development) in } \\
\text { synchronous and asynchronous settings } \\
\text { - Greater agency in the day-to-day activities in } \\
\text { class, e.g. acceptance by some PSTs to allow } \\
\text { their work to be used as teaching tools } \\
\text { - Effective team players when involved in group } \\
\text { projects shown in quality of end-of-year } \\
\text { projects } \\
\text { - Secure in one's learning and goal orientation: } \\
\text { My expectation was to finish the semester with } \\
\text { good marks....and that is how I ended (PST } \\
\text { portfolio, Nov. 2020) } \\
\text { - Confident and pride in one's achievements: I } \\
\text { gained confidence in myselfand in my own skills. } \\
\text { (PST portfolio, Nov. 2020) } \\
\text { - Increased interest in online synchronous } \\
\text { classes - attendance rates rise to } 85 \% \text { whereas } \\
\text { they fall alarmingly in other areas of the } \\
\text { program } \\
\text { - PSTs show less anxiety and nervousness during } \\
\text { summative testing } \\
\text { - Signs of more PSTs' active involvement in } \\
\text { synchronous videoconferencing- all cameras } \\
\text { open in one TE's final class. }\end{array}$} \\
\hline Activation & $\begin{array}{l}\text { PSTs share digitally recorded examples } \\
\text { of their own language speaking issues in } \\
\text { community forums to elicit feedback } \\
\text { from peers }\end{array}$ & \\
\hline Demonstrated & $\begin{array}{l}\text { TEs model ideal practice instead of } \\
\text { textbook theory in synchronous classes } \\
\text { to promote } Q \& A \text { and critical discussion }\end{array}$ & \\
\hline Application & $\begin{array}{l}\text {-Assessment becomes a group mediating } \\
\text { process rather than individual one } \\
\text {-Learning is measured by PSTs ability to } \\
\text { draw on newly acquired knowledge to } \\
\text { critically examen language for errors } \\
\text { rather than reproduce theory }\end{array}$ & \\
\hline Integration & $\begin{array}{l}\text {-Learning as a self-reflective process is } \\
\text { integrated through end-of-year digital } \\
\text { learning portfolios; PSTs attest to their } \\
\text { learning development and future } \\
\text { learning aspirations. } \\
\text {-Portfolios published in program } \\
\text { community site to share with peers for } \\
\text { their feedback. }\end{array}$ & \\
\hline $\begin{array}{l}\text { Collective } \\
\text { Knowledge }\end{array}$ & $\begin{array}{l}\text {-Individual student generated content, } \\
\text { eg writing assignments, are used in a } \\
\text { flipped classroom scenario by TEs in } \\
\text { synchronous classes to support peer } \\
\text { critical analysis and improvement. } \\
\text {-Formative test rubrics are co- } \\
\text { constructed by PSTs and TEs in a shared } \\
\text { drive. }\end{array}$ & \\
\hline Collaboration & $\begin{array}{l}\text { Groups of PSTs assume teaching roles in } \\
\text { presenting key topics of the course and } \\
\text { implicate peers in collaborative learning } \\
\text { activities during synchronous classes, } \\
\text { replacing TE lectures }\end{array}$ & \\
\hline Differentiation & $\begin{array}{l}\text { Freedom of choice offered to PSTs when } \\
\text { forming virtual groups and pairs in } \\
\text { breakout rooms }\end{array}$ & \\
\hline $\begin{array}{l}\text { Authentic } \\
\text { Resources }\end{array}$ & $\begin{array}{l}\text { Opportunities provided to PSTs to } \\
\text { attend faculty online webinars - experts } \\
\text { share insights about "real" classroom } \\
\text { issues, eg. learners with special needs }\end{array}$ & \\
\hline Feedback & $\begin{array}{l}\text { Increased feedback given by TEs on } \\
\text { virtual formative and summative tests } \\
\text { and learner-generated content. }\end{array}$ & \\
\hline
\end{tabular}


Changes in approach due to the alignment of the ID more closely to contemporary theory and goals were aimed first and foremost at providing opportunities for: a) building community, b) increased control i.e. agency, to the PSTs over learning content, activities, and importantly, assessment processes, c) promoting instances for social collaborative knowledge building through group work and d) having fun - an antidote to the pervasive stress as a result of the pandemic.

As noted above, the change process did not come easily to the 4 TEs as they attempted to migrate their courses to online modalities and to align their online pedagogical practices to contemporary theories (CharbonneauGowdy, Pizarro and Salinas, 2021). The transition was no less automatic for the PSTs. Many students, although not all, clung to the security of closed cameras for much of the second semester and opened them only in one of the TE's classes at the very end. On the other hand, data from several data sets revealed that the emerging shifts in pedagogical approach over the semester had a significant impact in other ways on learners. Many PSTs in the group displayed changes in their attitudes, behaviours, and ultimately their learning. In terms of attitude, several PSTs conveyed more positive feelings about the online classes. One student remarked: "Personally, starting the second semester was difficult and I didn't have much desire, but I was motivated to learn little by little, since, at the end of the day, I really want to live [learn] from this and be an excellent professional." (PST self-assessment portfolio, November 2020). In this excerpt, this PST acknowledges the difficulties he had in continuing to attend online classes at the outset of the second semester. At the same time, he recognizes that his increased investment levels, presumably due to the newly applied approaches and practices, allow him space for reflecting on his imagined identity - one that visualized himself in the future as an "excellent professional" teacher. We can speculate that as this student was given increased opportunities to invest more in the community of practice of the classroom and assume a more agentive role in his own learning and assessment process, he was able to produce 'new images of possibility and new ways of understanding' (Wenger, 2000). His testimonial reveals that these images and understandings are in relation to the world well beyond his engagement in acts in the immediate context of the online classroom (Norton, 2001) and speak to the long-term impact of the new ID practices. Another PST echoing similar positive sentiments, signalled not only a change of attitude but an awareness of the important role social interaction pedagogies played in his learning. In this student's end-of-semester self-assessment, he wrote: "I can say that I'm grateful of every recomendation (sic) and every feedback that teachers and my classmates gave me, because without it I could never be able to improve my skills." (PST learning portfolio, Nov. 2020)

An increase in responsible learning behaviours, reflective of changes in identity and investment in learning, were also evident. For example, although activity in the online forums improved slowly, in other assignments the PSTs became observably more involved. Volunteering to work in groups to teach course content in the videoconferencing sessions (with cameras open), giving constructive feedback to each other on the platform site and willingly sharing their work with those having difficulty, are a few examples. These examples speak to the agency and the accompanying responsibility several of the future teachers in the group were beginning to assume. These responsible behaviours went beyond their own immediate autonomous needs. Instead, they reflected a recognition of the value of shared knowledge.

Analysis of the data also revealed clear signs of changes in terms of learning - both cognitive and metacognitive. In an end-of-year self-assessment one PST reflecting back to her expectations at the beginning of the semester, recognizes progress in her learning trajectory through her words: "My expectation for this semester was to finish with good marks and new knowledge. Not being nervous on a Speaking Test. And that [is] how I have ended this semester." We speculate that the skills that this student has achieved and recognizes, demonstrated by her grades, new knowledge and confidence in speaking English are a testament to the instructional approaches the TEs mediated during the second semester. Clear instances like this of learning development, among others that surfaced in the data were not solely confined to increased skills in language teaching knowledge. There were also obvious signs of increased metacognition. Several PSTs evidenced this development in metacognition in both year-end self-assessment portfolios and interviews. For example, one PST shared:

For my second self-assessment I would like to give an overall view of this new and amazing semester. 2020 part 2 gave me so many life lessons that I am grateful for. I have learned so much during this term, not only about use of English, phonetics, listening, speaking, reading and writing but about myself, for example I became more aware of my learning process... (End-of-year self- assessment, Nov. 2020) 
We understand that the recognition this student has of her learning development, not just through her acquisition of skills but by a more advanced understanding of her personal cognitive processes, puts her in an ideal position for her trajectory as a professional educator.

Another example of this kind of metacognitive awareness can be seen in the following list shared by one particular PST as evidence of the changes she experienced over the semester:

Regarding to my relationship with my classmates, I had the chance to interact and get to know a little more a few of them and I am really happy about it, due to as a class we all should get along and support each other in this academic journey.

- I was way more participative in all my classes

- I was more constant with my studies.

- I was more motivated to learn as much as I could.

- I gained confidence in myself and in my own skills.

- I managed my time in a better manner.

- I improved my grades in speaking.

- I took delight in the learning pathway

In addition, this semester was more about get to know myself and [my] learning. (PST, End-of-year selfassessment, Nov. 2020)

In these words, we see a testimony to the student's evolving understanding of some of the critical conditions she needs for her learning to take place: the need for a community of learners, participation, time management, enjoyment, confidence, motivation, and consistency. We believe that a connection can be drawn between her awareness of these essential conditions for learning and the list of new pedagogical practices installed in the second semester in the move to a more contemporary learning-based design.

\subsection{Discussion}

Returning to our research questions (RQ1, RQ2), the data reveal the dire situation in which a majority of students, like their teachers (Charbonneau-Gowdy, Pizarro and Salinas, 2021), found themselves in the sudden transition to distance online learning. Clearly, most students in this context suffered from a lack of community and interaction both with their peers and teachers. This scenario left many despairing of their abilities to succeed in their courses and in learning. At least for many in the group of PSTs in the study, their attitudes and investment in learning were strikingly impacted - characterized by an obvious lack of commitment, interest, and willingness to engage in their studies online.

In the analysis of the second semester and the impact on learners of the new ID put into practice, (RQ3) we have painted a more positive picture. The changes in many of the PSTs in terms of their identities and investment in learning are substantiated with evidence of changes in their attitudes, learning behaviours and learning. What our analysis vividly reveals is that the majority of the PSTs showed positive and encouraging growth in their identities as learners. This growth was made visible through signs of: increased commitment; critical thinking in forums and discussions; confidence in one's own knowledge and sharing it with others; being active team players; openness to new ways of seeing and doing; and visionaries in terms of their imagined identities as professionals. The analysis also revealed a significant progress in many of the PSTs' learning trajectories, evidenced by signs of deep learning and metacognitive development not only in their current formal online learning contexts, but in envisaging their future lives as professionals. Based on this evidence, it is clear that in this particular context the theory-based changes made to pedagogical practices made a profound difference to the instruction, i.e. both teaching and learning, that took place online.

This picture of course is not a complete one. The data sets also revealed that a few PSTs witnessed continual frustration with online learning, fears, and hesitancy to engage with others, an ongoing lack of motivation, and anxieties about their progress over the semester. Sadly, four of the original seventeen students in the first-year group withdrew from the program. Whether these individuals were unable to cope with the changes in learning online as opposed to learning in traditional spaces or with the myriad implications of the pandemic crisis, the reasons are not clear. The study of human activity is always complex.

Some might question the connections we draw here between the positive changes we did uncover in the PSTs' identities and their learning, and the new theory-based pedagogical practices installed in the $2^{\text {nd }}$ phase of the 
study, based on changes to the ID. One could argue after all, that these encouraging signs in the PSTs are simply a result of the maturity and growth of these individuals over the period of their first year. There may be some validity to this argument. Yet, from our emic position working within the program, the clearly visible changes revealed in the PSTs identities and investment in learning between the end of the first and end of the second semesters, lead us to question that argument. Also, words such as: "this semester" and "2020 part 2" and "starting the second semester.. I was motivated little by little", that are cited in testimonials above, as well as others not reported here, helps give further credence to the conclusions we draw.

Another case in point relative to these conclusions pertains to further information collected from the larger student body. Space limitations here prevent us from providing details of the second university-wide student survey $(n=1,137)$ that was distributed across the institution at the end of at the end of 2020 , which in Chile is the end of the academic year. But it is important to point out that students responding to the survey were not exposed to the specific ID changes that the first-year PSTs experienced in this action research study, nor any systematic changes to the ID being used by other faculty. Essentially in summarizing the results of this second survey, there is clear evidence that minimal change occurred in both student's experiences online, their lack of confidence in online learning and their disparaging attitudes towards their ability to learn compared to the results reported in the first survey. We see these results as a further testimony to the value of the initiative that was instigated in the pedagogy program in putting contemporary theory to work in online practice.

\section{Conclusion}

We realize that we are not alone in asking the question why it has taken so long for many in education to connect theory to 'real' practice (Bonk, 2020). The chorus of voices that have been echoing this message has grown increasingly louder as conventional learning approaches and spaces are being more rapidly influenced by the impact of technology on every part of our lives. The current COVID crisis has magnified these voices exponentially. Some see confusion and insurmountable challenges; others see opportunities for positive change (Diehl, 2020). Our study was aimed at the latter by taking concrete positive steps to respond to this call. The small size of the inquiry as well as the short timeline of the study can be considered limitations. Yet, we believe the strong findings offer a clearly applicable and realistic framework for addressing many of the roadblocks that scholars and many stakeholders in education at the macro, meso, micro levels have failed, at least until now, to overcome (Charbonneau-Gowdy and Chavez, 2019). The framework is built on clear steps: 1) mediate highly structured and contextualized instructional designs based on contemporary learning theories and 2) apply these structures to well defined instruction decisions, both learning and teaching practices in e-learning settings. Our study has shown that taking these steps has positive implications for learning and learners -the kinds of learning and learners many of us have been struggling to foster for quite some time. It will require an abundance of similar empirical study initiatives in a broad range of contexts to determine the viability and sustainability of this initial attempt at finally drawing theory into practice online. Education is being shaped by this pandemic crisis in ways that are still to be determined. Projections of an educational system more dependent on online learning seem assured. We can continue to focus on theory, or practice, but given the findings of this study and the cries for help from many stakeholders in the field, now seems the ideal moment to succeed finally in aligning both.

\section{References}

Adinda, D. and Mohib, N., 2020. Teaching and instructional design approaches to enhance students' self-directed learning in Blended Learning environments. The Electronic Journal of e-Learning, 18(2), pp. 162174.

Allen, E. Seaman, J., Poulin, R. and Straut, T., 2016. Online report card. Tracking online education in the United States. Available at: https:// onlinelearningsurvey.com/reports/onlinereportcard.pdf [Accessed 24 October 2021]

Bonk, C. J., 2020. Pandemic ponderings, 30 years to today. Distance Education, 41(4), pp. 589-599.

Branch, R. M. and Dousay, T.A., 2015. Survey of instructional development models, $5^{\text {th }}$ Ed. Bloomington, IN: Association for Educational Communications and Technology.

Brown, K. and Charlier, S., 2013. An integrative model of e-learning use: Leveraging theory to understand and increase usage. Human Resource Management Review, 23(1), pp. 37-49.

Castro, M. and Tumibay, G., 2021. A literature review: Efficacy of online learning courses for higher education institution using meta-analysis. Education and Information Technology, 26(2), pp. 1-19.

Charbonneau-Gowdy, P., Pizarro, J. and Salinas, D., 2021. How it started/ how it's going: Aligning Teacher Educators' designs, approaches and identities in our new online reality. 7th International Conference on Higher Education Advances (HEAd'21), pp. 1259-1266. Valencia, Spain, June 22-23, 2021. Valencia: Editorial Universitat Politècnica de València.

Charbonneau-Gowdy, P. and Chavez, M., 2019. 3-M model for uncovering the impact of multi-level identity issues on learners' social interactive engagement online. Electronic Journal of e-Learning 17(2), pp. 131-143. 
Charbonneau-Gowdy, P. and Herrera, M., 2019. 'Breaking bad': Overcoming barriers preventing Higher Education faculty from offering quality blended learning programs. Proceedings of the 18th European Conference on e-Learning (ECEL), pp. 128-136, Reading, UK: Academic Conferences Limited

Charbonneau-Gowdy, P., 2018. Beyond stalemate: Seeking solutions to challenges in online and blended learning Programs, Electronic Journal of e-Learning 16(1), pp. 56-66.

Darvin, R. and Norton, B., 2016. Investment and language learning in the 21st Century. Langage et Société, 157 (3), pp. 1938.

Denzin, N.K., and Lincoln, Y.S., 2005. Introduction: The discipline and practice of qualitative research. In N.K. Denzin and Y.S. Lincoln (Eds.), The Sage handbook of qualitative research (2011 ed.). Thousand Oaks, CA: Sage.

Diehl, W., 2020. Opportunities and change amidst debate, confusion and challenges in education. American Journal of Distance Education, 34(4), pp. 259.

Flores, M.A. and Gago, M., 2020. Teacher education in times of COVID -19 pandemic in Portugal: National, institutional, and pedagogical responses. Journal of Education for Teaching, 46(4), pp. 507-576.

Gardner, J., 2011a. Investigating theoretical support for first principles of instruction: a systematic review. Midwest Journal of Educational Communication and Technology, 5(1), pp. 8-17.

Garrison, R.R. and Vaughan. N.D., 2013. Institutional change and leadership associated with blended learning innovation: Two case studies. The Internet and Higher Education, 18, pp. 24-28.

Garrison, D. R. and Cleveland-Innes, M., 2005. Facilitating cognitive presences in online learning - Interaction is not enough. The American Journal of Distance Education, 19(3), pp. 133-148.

Garrison, D. R. and Kanuka, H., 2004. Blended learning: Uncovering its transformative potential in higher education. Internet and Higher Education, 7, pp. 95-105.

Joshi, O., Chapagain, B. Kharel, G., Poudyai, N.C., Murray, B.D. and Mehmood, S. R., 2020. Benefits and challenges of online instruction in agriculture and natural resource education. Interactive Learning Environments, 29(2), 1-12.

Judd, J., Rember, B., Pellegrini, T., Ludlow, B and J. Meisner. 2020. "This is not teaching": The effects of COVID-19 on teachers. Available at: https://www.socialpublishersfoundation.org/knowledge_base/ this-is-not-teaching-theeffects-of-covid-19-on-teachers/ [Accessed 24 October 2021]

Lave, J. and Wenger, E., 1991. Situated learning. Legitimated peripheral participation. Cambridge, MA: Cambridge University Press.

Margaryan, A., Bianco, M. and Littlejohn, A., 2015. Instructional quality of Massive Open Online Courses (MOOCs). Computers and Education, 80, pp. 77-83.

Medina, L., 2018. Blended learning: Deficits and prospects in higher education. Australasian Journal of Education Technology, 34(1), pp. 42-56.

Merrill, M. D., 2013. First principles of instruction: Identifying and designing effective, efficient and engaging instruction. Hoboken, NJ: Pfeiffer/John Wiley \& Sons.

Miles, M. B., Huberman, A. M., and Saldaña, J., 2014. Qualitative data analysis: A methods sourcebook (3rd ed.). Los Angeles: Sage.

Moralista, R. and Oducado, R., 2020. Faculty perception toward online education in a state college in the Philippines during the Coronavirus disease 19 (COVID-19) pandemic. Universal Journal of Education Research, 8(10), pp. 4736-4732. DOI: 10.13189/ujer.2020.08 1044.

Naidu, S., 2020. It is the worst - and the best - of times! Distance Education 41(4), pp. 425-428.

Norton, B., 2001. Non-participation imagined communities and the language learner. In: M. Breen, ed., Learner contributions to language learning: New directions in research. Harlow, England: Pearson Education. pp. 159-171.

OECD, 2020. Education responses to COVID-19: Embracing digital learning and online collaboration. Available at: https://www.oecd-ilibrary.org/search?value1=Education+responses+to+COVID-

$19 \% 3 \mathrm{~A}+$ Embracing+digital+learning+and+online+collaboration\&option1=quicksearch\&facetOptions=51\&facetNames =pub igold facet\&operator51=AND\&option51=pub igold facet\&value51=\%27igo\%2Foecd\%27\&publisherld=\%2Fco ntent\%2Figo\%2Foecd\&searchType=quick. [ Accessed 22 November 2021].

Pange, A. and Pange, J., 2011. Is E-learning based on learning theories? A literature review. International Scholarly and Scientific Research and Innovation, 5(8), pp. 932- 936.

Philipsen, B., Tondeur, J., McKenney, S., Pynoo, B. Vanslambrouck, S., and Zhu, C., 2019. Examining lived experiences in a professional development program for online teaching: A hermeneutic phenomenological approach. Australasian Journal of Educational Technology, 35(5), pp. 46-59.

Picciano, A.G., 2017. Theories and frameworks for online education: Seeking an integrated model. Online Learning, 21(3), pp. 166-190. doi: 10.24059/olj.v21i3.1225.

Prinsloo, P., 2016. (Re)considering distance education: exploring its relevance, sustainability and value contribution. Distance Education, 37(2), pp. 139-145.

Ribiero, R., 2020. How university faculty embraced the remote learning shift.'EdTech Magazine April 14.

Riverin, S. and Stacey, E., 2008. Sustaining an online Community of Practice: A case study. Journal of Distance Education, 22(2), pp. 43-58.

Schleicher, A., 2021. What will education look like in 20 years? Here are 4 scenarios. World Economic Forum Report 2020. Available at: https://www.weforum.org/agenda/2021/01/future-of-education-4-scenarios/ [Accessed 24 October 2021] 
Scull, S., Phillips, M., Sharma, U. and Garnier, K., 2020. Innovations in teacher education at the time of COVID19: an Australian perspective. Journal of Education for Teaching, 46(4), pp. 497-506.

Seels, B. and Richey, R., 1994. Instructional technology: The definitions and domains of the field. Washington, DC: Association for Educational Communications and Technology.

Smith, K., Gamlem, S. M., Sandal, A. K., and Engelsen, K. S., 2016. Educating for the future: A conceptual framework of responsive pedagogy. Cogent Education, 3(1). DOI 10.1080/2331186X.2016.1227021

UNESCO, 2020. COVID-19: A global crisis for teaching and learning. Available at: https://teachertaskforce.org/knowledgehub/covid-19-global-crisis-teaching-and-learning [Accessed 22 November 2021].

UNESCO, 2021. One year into the \#COVID 19 crisis: Students and teachers share their stories. Available at: https://en.unesco.org/covid19/educationresponse/learningneverstops [Accessed 24 October 2021]

Voogt, J., Erstad, O. Dede, C. and Mishra, P., 2013. Challenges to learning and schooling in the digital networked world of the $21^{\text {st }}$ century. Journal of Computer Assisted Learning, 29(5), pp. 403-413.

Vygotsky, L. S., 1981. The genesis of higher mental functions. In: J. V. Wertsch (Ed.), The concept of activity in Soviet psychology. Armonk, NY: M.E. Sharpe.

Wenger, E., 1998. Communities of practice: Learning, meaning, and identity. Cambridge: Cambridge University Press.

Whiting, K., 2021. Is this what higher education will look like in 5 years? World Economic Forum Report. Available at: https://www.weforum.org/agenda/2020/11/higher-education-online-change-cost-covid-19 [Accessed 24October 2021]

Yuan, J and Kim, C., 2014. Guidelines for facilitating the development of learning communities in online courses. Journal of Computer Assisted Learning, 30(3), pp. 220-232. 